\section{UNIVERSITY AND EDUCATIONAL.}

\section{INTELLIGENCE}

CAMBRIDGE, May 30.-The Sheepshanks Astronomical Exhibition has been adjudged to John Edward Aloysius Steggall, scholar of Trinity College.

The twenty-second annual report of the Botanic Garden Syndicate has been issued. It is stated that during the past year much attention has been paid to the labelling of the arranged trees, shrubs, and herbaceous plants in the open ground, and it is believed that they all, or nearly all, are correctiy and legibly named. There has not been time, without neglecting other important work, to name with similar completeness the plants scattered in the belt. It is believed that very few of the plants in the houses are without names, although a few duplicate specimens may be in that condition. About 1,700 new labels have been written. The culture of the plants is such as to give satisfaction to the syndicate. About r jo species of herbaceous plants have been raised from seed to supply the places of those which have died. Among the presents acknowledged are packets of seeds from the Indian Botanic Gardens, from Baron F. v. Mueller, and five large ferns from Australia from the last-mentioned gentleman.

OXFORD. - At the ensuing commemoration the honorary degree of D.C.L. will be conferred upon Mr. J. Evans, the distinguished antiquary; Di. Harold Browne, the Bishop of Winchester; and Lord Coleridge. It is probable that degrees will be conferred on certain other distinguished persons, whose names, however, it would be premature to announce at present.

On November 23 next there will be an election to a Brackenbury Natural Science Scholarsnip at Balliol College, worth 8ol. a year, tenable during residence for four years, open to all such candiciates as shall not have exceeded eight terms from matrica. lation. Papers will be set in (I) Mechanical Philosophy and Physics, (2) Chemistry, (3) Physiology; but candidates will not ve expected to offer in more than two of these.

DUSHAM. - The University Mathematical Scholarship has been awarded to Mr. F. W. Sanderson, Hatfield Hall.

THs. UinIVERsix les BHL. - The attempt was made iwice on Nonday in the House of Commons to get a clause inserted in the Universities Bill abolishing Clerical Fellowships. As might have been expected, the attempt failed, though in the case of Mr. Goschen's motion by a very narrow majority-only 9 .

UNIVERSTTES AND NATIONAL LIFE. - The following forcible remarks on universities and national life occur in the address of Prof. Sylvester at the Johns Hopkins University, to which we have already referred:-" The mention of Germany brings to my mind the importance of universities to the maintenance or development of a national spirit in the countries in which they are fostered and carried on with an animus free from local or sectarian prejudices. I think that there can be little doubt that the greatest fact in modern history, the consolidation of the German empire, the resurrection of the German people, is mainly to be attributed to the feeling of brotherhood and the spirit of nationality kept alive in those ganglions of thought, those centres of intellectual activity, the German universities. It is the university professors who have made German unity a possibility, and I cannot but deplore the unpatriotic short-sightedness of those in my own country who, until so late a period, have struggled, and still covertiy struggle, to make our universities in England not the representatives of the universal English mind, but the monopoly of a party and the appanage of a sect."

\section{SCIENTIFIC SERIALS}

American Fournal of Science and Arts, May.-On vortex rings in liquids, by J. Trowbridge.-An account of the discoveries in Vermont Geology of the Rev. Augustus Wing, by J. D. Dana.- Notes on the history of Helianthus tuberosus, the so-called Jerusalem artichoke, by J. H. Trumbull and Asa Gray. - A new investigation of one of the laws of friction, by A. S. Kimball.-Examination of American columbic acid minerals, by I. Lawrence Smitb. - On the sensitiveness to light of various salts of silver, by M. Carey Lea.

Posgendorff's Annalen der Physik und Chemie, No. 3.-On the cohesion of salt solutions, by G. Quincke.-On the theory of stationary electric flow in curved surfaces, by A. Topler.-On normal magnetisation, by $M$. Petruscheffsky...-On the tempe. rature in the conducting wire of a galvanic current, by $M$. Streintz. - Remarks on a statement of $\hat{F}$. Kohlrausch on therrioelectricity, by M. Clausius, - On the galvanic resistance of haloid compounds, by M. Lenz.--On the dynamical significance of the quantities occurring in the mecbanical theory of heat, by $M$. Szily.-On a paradox of the mechanical theory of heat, by $M$. Ritter.-Researches on the movements of radiating and irradi. ated bodies (concluded), by $M$. Zöllner,-On the connection between absorption and dispersion, by M. Ketteler.-On the neutral combs of the Holtz machine, by M. Riess.-Galvanic dipping battery for elements with two liquids, by M. Hert $z$.

Reale Istituto Lombardo di Scienze e Lettere. Rendiconti, vol. x. fasc. iv. v. vi. - Observations on Borrelly's comet, by M. Schiaparelli.-Ditto by P. Secchi. - On a singular congenital and lipomatous pigmeritary alteration, by M. Scarenzio.-Contribution to the study of Addison's disease, by M. Vals:ani, - New barometric formula for the measurement of altitudes, and the reduction of barometric heights to the sea-level, by M. GrassiGeneral method of obtaining diagrams of the motion of a point, by $M$. Padelletti. - On algebraic differential equations of the first order and first degree, by M. Pincherle. - On some questions of electrostatics, by $M$. Beltrami. - On some unpublished letters from Lagrange to Kuler, by $M$. Schiaparelli, - Origin and anatomy of intestinal diverticula, and their application in practical surgery, by M. Sangalli.-On a new species of Dochmius (Dochmius balsami), by MM. Parona and Cirassi.

\section{SOCIETIES AND ACADEMIES LONDON}

Royal Society, May 31.- "On the Amplitude of Sound. Waves," by Lord Rayleigh, M.A., F.R.S.

Scarcely any attempts have been made, so far as I am aware, to measure the actual amplitude of sound-bearing waves, and indeed the problem is one of considerable difficulty. Even if the measurement could be effected, the result would bave reference only to the waves actually experimented upon, and would be of no great value in the absence of some means of defining the intensity of the corresponding sound. It is bad policy, however, to despise quantitative estimates because they are rough, and in the present case it is for many reasons desirable to have a general idea of the magnitudes of the quantities with which we have to deal. Now it is evident that a superior limit to the amplitude of waves giving an audible sound may be arrived at from a knowledge of the energy which must be expended in a given time in order to generate them, and of the extent of surface over which the waves so generated are spread at the time of hearing. Anl estimate founded on these data will necessarily be too hirgh, both because sound-waves must suffer some dissipation in their progress, and also becalse a part, and in some cases a large part, of the energy expended never takes the form of sound-waves at all.

The source of sound in my experiment was a whistle, mounted on a Wolf's bottle, in conneztion with which was a syphon manometer, for the purpose of measuring the pressure of wind. This apparatus was blown from the lungs through an indiarubber tube, and with a little practice there was no difficulty in maintaining a sufficiently constant blast of the requistte duration. The most suitable pressure was determined by preliminary trials, and was measured by a column of water $9 \frac{1}{2}$ centimetres high.

The first point to be determined was the distance from the source to which the sound remained clearly audible. The experiment was tried in the middle of a fine still winter's day, and it was ascertained that the whistle was heard without effort at a distance of 820 metres. In order to guard against any effect of wivd, the precaution was taken of repeating the observation with the direction of propagation reversed, but without any difference being observable.

The only remaining datum necessary for the calculation is the quantity of air which passes through the whistle in a given time. This was determined by a laboratory experiment. The indiarubber tube was put into connection wit' the interior of a rather large bell-glass open at the bottom, and this was pressed gradually down into a large vessel of water in such a manner that the manometer indicated a steady pressure of $9^{\frac{1}{2}}$ centimetres. The capacity of the bell-glass was 5,200 cubic centimetres, and it was found that the supply of air was sufficient to last $26 \frac{1}{2}$ seconds of time. The consumption of air was therefore 196 cubic centimetres per second. 
In working out the result it will be most convenient to use onsistently the C. G. S. system. On this system of measurement the pressure employed was $9 \frac{1}{2} \times 98 \mathrm{I}$ degrees per square centimetre, and therefore the work expended per second in generating the waves was $196 \times 9 \frac{1}{2} \times 981$ ergs. Now the mechanical value of a series of progressive waves is the same as the kinetic energy of the whole mass of air concerned, supposed to be moving with the maximum velocity of vibration $(v)$; so that, if $S$ denotes the area of the wave front considered, $a$ be the velocity of sound, and $\rho$ be the density of air, the mechanical value of the waves passing in a unit of time is expressed by $\frac{x}{2} \mathrm{~S} \cdot a \cdot \rho \cdot v^{2}$, in which the numerical value of $a$ is about 34,100 , and that of $\rho$ about 0013 . In the present application $S$ is the area of the surface of a hemisphere, whose radius is 82,000 centimetres ; and thus, if the whole energy of the escaping air were converted into sound, and there were no dissipation on the way, the value of $v$ at the distance of 82,000 centimetres would be given by the equation-

$$
v^{2}=\frac{2 \times 196 \times 9 \frac{1}{2} \times 98 \mathrm{r}}{2 \pi(82000)^{2}} \times 34100 \times \frac{10013}{00},
$$

whence

$$
v={ }^{\circ} \mathrm{OO} 4 \mathrm{f} \text { centimetres per second. }
$$

This result does not require a knowledge of the pitch of the sound. If the period be $\tau$, the relation between the maximum excursion $x$ and the maximum velocity $v$ is

$$
x=\frac{v \tau}{2 \pi} \text {. }
$$

In the present case the note of the whistle was $f^{\text {iv }}$, with a frequency of about 2730 . Hence

$$
x=\frac{.0014}{2 \pi \times 2730}=10^{-8} \times 8.1,
$$

or the amplitude of the aerial particles was less than a ten millionth of a centimetre.

I am inclined to think that on a stili night a sound of this pitch, whose amplitude is only a hundred millionth of a centimetre, would still be andible.

Linnean Society, May 24.-Annual General Meeting.Prof. Allman, F.R.S., president, in the chair.- -The Senior Secretary (Mr. Currey) read his report, among other items, mentioning that twelve fellows and five foreign members had lied during the past year. On the other hand forty-three fellows, three foreign members, and one associate had been elected. Of active scientific workers that had passed away, $J$. Scott Bowerbank, Edward Newman, and Alfred Smee called for special mention; the labours of the first named, in a previously little-worked department, the sponges, marking an epoch in British natural history. A passing tribute was due to the memory of the foreign members that had died during the year, for von Baer, Braun, De Notaris, Ehrenberg, and Hofmeister in their several departments worthily represented biological science in its broad aspects.--Mr. Gwyn Jeffreys, treasurer, in his financial statement, showed an increased balance in favour of the Society, and this, notwithstanding extra outlay in valuable additions to the library, improvements in the Society's scientific publications, \&c. The demise of the late Charles Lambert, F.L.S., had brought the handsome bequest of $500 l$. to the funds of the Society.--The president and officers were re-elected and the following gentlemen, viz., Lieut.-Col. Grant, C.B., W. Carruthers, R. Hudson, Dr. J. Millar, and Dr. R. C. A.' Prior were elected into council in lieu of the subjoined, who retired by rotation:-G. Bentham, Gen. Scott, C.B., R. B. Sharpe, H. T. Stainton, and C. Stewart. We elsewhere give an abstract of the presidential address, devoted to a résumé on "Recent Researches among the Lower Sarcode Organisms," a subject of daily increasing interest.

Meteorological Society, May I6.-Mr. H. S. Eaton, M.A., president, in the chair.-Messrs. Stephen Bretton, J. Gulson Burgess, David Milne Home, and F. Gartside Tippinge were elected fellows of the Society. - The following papers were read :-An improved form of mercurial barometer, by Mr. R. E. Power, F.M.S. The improvement consists in the use of a double column of mercury, so that in the event of a vacuum being formed by the escape of some mercury into the cistern, the shock is no longer felt by the tube but in the first place is received by the mercury alone and then reflected much diminished into the cistern, where it is modified by the presence of the atmosphere. At the same time, owing to the peculiar construc- tion of the cistern, the probability of any mercury leaving the tubes is much less than in the case of the standard barometers at present in use. It is also believed that the employment of the double tube will do away with the necessity of boiling the mer. cury. - The relation between the upper and under currents of the atmosphere around areas of barometric depression, by the Rev. W. Clement Ley, F.M.S. This paper gives a description of the mean directions of the movements of cirrus clouds over the different segments of areas of depression. The subject is treated on its observational side, as it is not yet considered ripe for much theoretical discussion, but one or two points seem likely to throw some light on the theory of the movements of the atmosphere. The direction of the upper currents round a depression is found to be most intimately related to the direction in which the depression itself is progressing. In the rear of a depression where the mean direction of the surface winds is nearly parallel to the isobars, or at right angles to the radius, the cirrus current almost coincides with the surface wind, except near the central calm. In the front of the depression on the other hand, where there is the greatest indraught near the earth's surface, the upper currents flow greatly away from the centre. The current in the rear of a depression has therefore the greatest, and that in the front the least vertical depth. The majority of our depressions travel towards some point between N. and E., and so far as the author has been able to calculate, the mean height of our southeasterly winds is not half that of our north-westerly winds, even supposing the latter to extend no higher than the stratum of cirrus. The angle of deviation increases with the increase of friction; and it is possible, therefore, that the great incurvation of the surface winds in the front of a depression is closely related to the greater amount of friction which they encounter, for they are comparatively shallow currents, and experience resistance above as well as at their base. The contrast between the upper currents on the right and those on the left of the trajectory is quite as remarkable as that between the upper currents in the tront and in the rear, and it is very constant and well-marked in its general character. As regards the centre, the upper-current, when traceable over this district, commonly coincides, or very nearly, with the wind previously felt at the earth's surface. Contributions to the meteorology of the Pacific-the Island of Rapa, by Robert H. Scott, F.R.S. Rapa is a small island, eighteen miles in circumference, in the South Pacific, in latitude $27^{\circ} \mathrm{S}$. and longitude $144^{\circ} \mathrm{W}$. The observations were made by Capt. D. E. Mlackellar, on board the depôt ship Medas, during the period extending from 1867, December 15, to 1869, May 27. The climate appears to be an equable one.

Physical Society, May 26.--Prof. G. C. Foster, president, in the chair. - The following were elected members of the Society :-Lient-Col. A. C. Campbell, Dr. H. Debris, F.R.S., Mr. W. T. Thiselton Dyer, M.A., B.Sc., W. Jack, M.A., and Capt. Sale, R.E.-Lieut.-Colonel Campbell explained and exhibited a double slit which he has employed for measuring the distances between the lines in the spectrum and finds of great service in cases where the illumination is so slight as to preclude the possibility of using the ordinary micrometer. One slit remaining stationary the other can be moved at right angles to its direction by means of a very delicate micrometer screw of 200 threads to the inch, the graduated head of which is capable of distinctly indicating one-five-millionth of an inch in the motion of the slit. If now a reading of the micrometer be taken when the slits are superposed and form one continuous slit, and a second reading when any given line has been superposed upon any other line at a moderate distance from it, the difference betw'een these readings will enable us at once to ascertain the distance between the lines if the micrometer be calibrated in terms of the spectrum as seen in the observing telescope. The author has made several measurements with this apparatus, and finds it to be capable of extreme accuracy, but it is of course essential that the movable slit remains within a moderate distance of the axis of the collimator. He then described a simple arrangement for automatically fixing a prism, when placed on the table of a goniometer at the angle of minimum deviation when different coloured rays are under examination. To the arms which support the telescopes of the goniometer are attached two short links of equal lengths connected at their extremities with a nut sliding freely. on an arm which is fixed radially to the centre table of the instrument. The prism is held on this table with its base at right angles to this arm, and it thus remains adjusted for all the rays of the spectrum.-Mr. O. J. Lodge then read two papers by Profs. Ayrton and Perry, jointly, 
of the Imperial College of Engineering, Tapan. The first contains an account of an elaborate series of experiments on ice as an electrolyte. They state as a result of their experiments that the capacily per cub. cent. of ice at $-13^{0 .} 5 \mathrm{C}$. is 0.002 micro-farad, and the specific inductive capacity is 22,160 (that of air being called unity), while that of water at $\delta^{\circ} \cdot 7 \mathrm{C}$. is about 2,240 times this amount. Commencing with ice at $-13^{\circ} \cdot 6 \mathrm{C}$ the temperature was allowed to rise and the conductivity determined by galvanometer readings. From these a very regular curve was deduced which shows that the conductivity increases regularly, and that there is no sudden rise in passing from the solid to the liquid state. The apparatus was also employed for determining the electromotive force of polarisation currents at different temperatures by replacing the copper by a zinc disc.-The second communicaiton contained suggestions for experiments on the viscosity of water and other liquids. It is accompanied by working drawings of an apparatus which the authors have designed for determining the relation between the viscosity of a liquid and the velocity of a surface moving in contact with it. They have, however, no facilitics for making such an apparatus, and therefore place it at the service of any one who may be willing to study the subject.

Victoria Institute, June 4.--At the Annual Meeting of this Insitute, the address was delivered by Mr. J. E. Howard, F.R.S.-Capt. F. Petrie (the honorary secretary) read the elcrenth annual report; Io7 members and associates had joincil during the year, and the total number had risen to over 700 , two-thirds of whom were country and foreign members.

Institution of Civil Engineers, May 29.-Mr. George Robert Stephenson, president, in the chair.-A paper was read on an economical method of manufacturing charcoal for gunpowder, by Mr. George Haycrait, F.C.S.

\section{PARIS}

Academy of Sciences, May 2\&, M. Peligut in the chair.Some remarks were made on $M$. Roudaire's Algerian scheme. MT. de Lesseps thought it practicable and useful; M. d'Abbadie ciesired that study might be given for a whole year to the quanticy of evaporation and the résime of the winds in that resion, \&c. - The following papers were read :-Reply to M. Tacchini's note inserted in last Comptes Rendus, by M. Janssen. While accepting $M$. Tacchini's figures in comparison of maximun and nuinimum years, he yet holds that the numerous and rapid appearance and disappearance of spors witnessed during the past year indicates very violent movements of matter.-On Gay Lilisac's law of volumes, reply to M. Saint Claire Deville, by M! Wurtz. The system of chemical equivalents which prevailed about 1840 over the atomic notation of Berzelius, has not taken account of Gay Lussac's discoveries on the combinations of gases, and the maintenance of the principle of equivalence in chemical notation would bring science back to the times of Dalton, Wollaston, and Richter, which would be an anachronism. - Reply to M. Wurtz's note on the law of Avogadro and the atomic theory, by M. Berthelot.-Experimental critique on the glycogenetic iunction of the liver, iy $\mathrm{M}$. Cl. Bernard. $\mathrm{He}$ proves the function directly during life, laying bare the liver in a dog, cutting off a piece of it, which is then put into boiling water. The tissue contains a proportion of sugar varying from I to 3 per 1,000 . The influence of vivisection does not cause variation in the quantity, uniess the circulatory and respiratory functions are greatly disturbed. M. Bernard also demonstrates that the saccharine matter continues to be formed in the liver after death.-Observations on the work presented to the Academy by M. Villarceau, entitled the "Nouvelle Navigation," by $M$. Mouchez. He objects to the title; and the analytic method proposed (application of Taylor's series in place of the old formula) though good in theory, is found impracticable. The graphic method is nearly the same, according to M. Mouchez, as he has himself long practised and recommended. Lastly there is but rare need to use M. Viliarceau's new process for determining the most probable point.-- On an algebraic method for obtaining the ensemble of the fundamental invariants and covariants of a binary form, and of any combination of binary forms (continued), by Prof. Sylvester.-Description of new manœuvres executed with the economising apparatus at the dam of Aubois, by $M$. de Caligny.-Experiments made in order to appreciate the diffusion of the vapours of sulphide of carbon introduced into the ground as an insecticide, by $M$. Gastine. In permeable soil the diffusion reached a maximum radius of about $\mathrm{I}$ metre about the hole of injection (which received 20 grammes of the sulphide). The vapours persisted at $30 \mathrm{~cm}$. distance from March I to 5 , or about 100 hours; nearer the hole, 150 hours. In clayey soil the diffusion was as extensive, and the persistence was about twenty-four hours more. - - Hisiorical remarks on the theory of movement of one or several bodies of constant or variable forms, in an incompressible fluid; on the apparent resultant forces and on the experiments relating thereto, by M. Bjerknes.-On Gauss's formula of quadrature, by M. Callandreau.-Thermal researches on the substituted anilines, by M. Longuinine. - Electrolysis of ordinary pyrotartaric acid, by MM. Reboul and Bourgoin. This acid is very stable; it is electrolysed like mineral acids, and is in this respect quite unlike succinic acid, which is decomposed easily.-Researches on the synthesis of acids of the series $\mathrm{C}_{n} \mathrm{H}_{2 \mathrm{n}-2} \mathrm{O}_{2}$ and $\mathrm{C}_{n} \mathrm{H}_{2 n_{21}-4} \mathrm{O}_{2}$; allylic and diallylacetic acids, by MI. Reboul. - On the decomposition of carbonic acid in the solar spectrum by the green parts of plants, by M. Timiriazeff. A spectrum was formed with a bisulphide of carbon prism and a trough containing chlorophyll solution was put in the path of the rays. Next were interposed in a row five vessels inverted over mercury, each containing air with about 5 per cent. carbonic acid, and these vessels received green organs of plants (pieces cut from a bamboo leaf). The vessels, being in different parts of the spectrum, were left there six to ten hours on fine days in July, and the gas was afterwards analysed. The maxiInum of decomposition of $\mathrm{CO}_{2}$ was always found in the vessel corresponding to the position of the characteristic absorption band of chlorophyll ; in orange, yellow, and green, the amount of decomposition showed successive decrease, and in red there was even production of $\mathrm{CO}_{2}$ through respiration. - On the nature and signification of the small red corpusiles of the bluod, by M. Hayem. He concludes that they are young corpuscles incompletely developed.-On the changes of volume, and the delivery of the heart, by $M$. François-Franck. His method was to connect the cavity of the pericardium (in live dogs) with one of Marey's registering apparatuses. The heart increasing in volume in diastole clrove a certain quantity of air into the tambour, while the contraction in systole permitted return of this air. - On the histological alterations of the uterus in their relations to the principal diseases of this organ, by $f i t$. Courty. - Statistical Researches on the Sologne, especially with regard to recruiting and movement of the population, by $M$. Coste.-On a process for recognising the presence of fuchsine in wines, by M. Baudrimont. A drop of fuchsinated wine left a few seconds on the skin of the hand, produces a mark which cannot be washed out with water.

\section{GöTTINGen}

Royal Academy of Sciences, January 3I.-Report on the Botanical Institute of Göttingen University for 1876 .

February 2I.-A contribution to the theory of reflectionphenomena, by M. Rethy.

March 2I. Separation of arsenic from nickel and cobalt.

April 4.-On the electric conductivity of aqueous solutions, especially of salts of the alkalies and alkaline earths, caustic alkalies, and some acids, by M. Kohlrausch.

\section{CONTENTS}

PaGe

The Antiquity of MaN

The Valuk of Naturad History Museums. By Prof. W. Bord Physiological fisthetics. "By George j. Romanté • • • •

OUR BOOK SHRIF MoOK SHRLF :-

Mueller's "Select Plants for Industrial Culture in Victoria" . . 100

Russell's "Notes on the Ancient Glaciers of New Zead rnd" . . 10s TTERS TO THR EDITOR:-

Nectar-secreting Glands. -Fraxcis Darwin . . . . . . . 100

Quartzite Implements at Brandon. Tromas BeLT : : : : ror

The Migration of the Swiss Miocene Flora.-Rev. Grorge

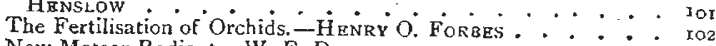

New Meteor Radiant.-W. F. Denning . . . . . . . 102

Our Astronumical. COLUMN :-

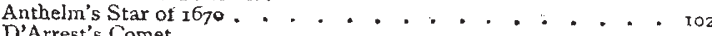

D'Arrest's Comet . . . . . . . : . . . 102

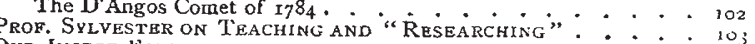

OUR INSECT Foes

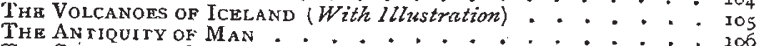

The GREenwich ObSERVATORY Report

ReCENT Researches among the Lower Sarcode Organismis. By Prof. Allman, F.R.S. * . . . . . . . . Iro The Norwegian DeEp-Sza Expedition. By Dr. Hohn: : iro

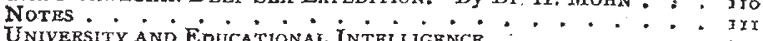

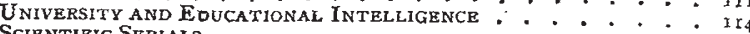

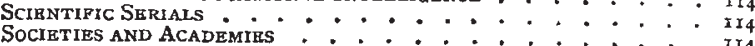

